\title{
OVERDENTURE UTILIZING ACCESS POST SYSTEM - A CASE REPORT
}

\author{
Sumit Aggarwal', Shalu Jain ${ }^{2}$, Pradeep Raghav ${ }^{3}$ \\ ${ }^{1}$ Reader, Department of Prosthodontics, Subharti Dental College, Uttar Pradesh, India \\ ${ }^{2}$ Sr. Lecturer, Department Of Orthodontics, Subharti Dental College, Uttar Pradesh, India \\ ${ }^{3}$ Professor \& Head, Department of Orthodontics, Subharti Dental College, Uttar Pradesh, India
}

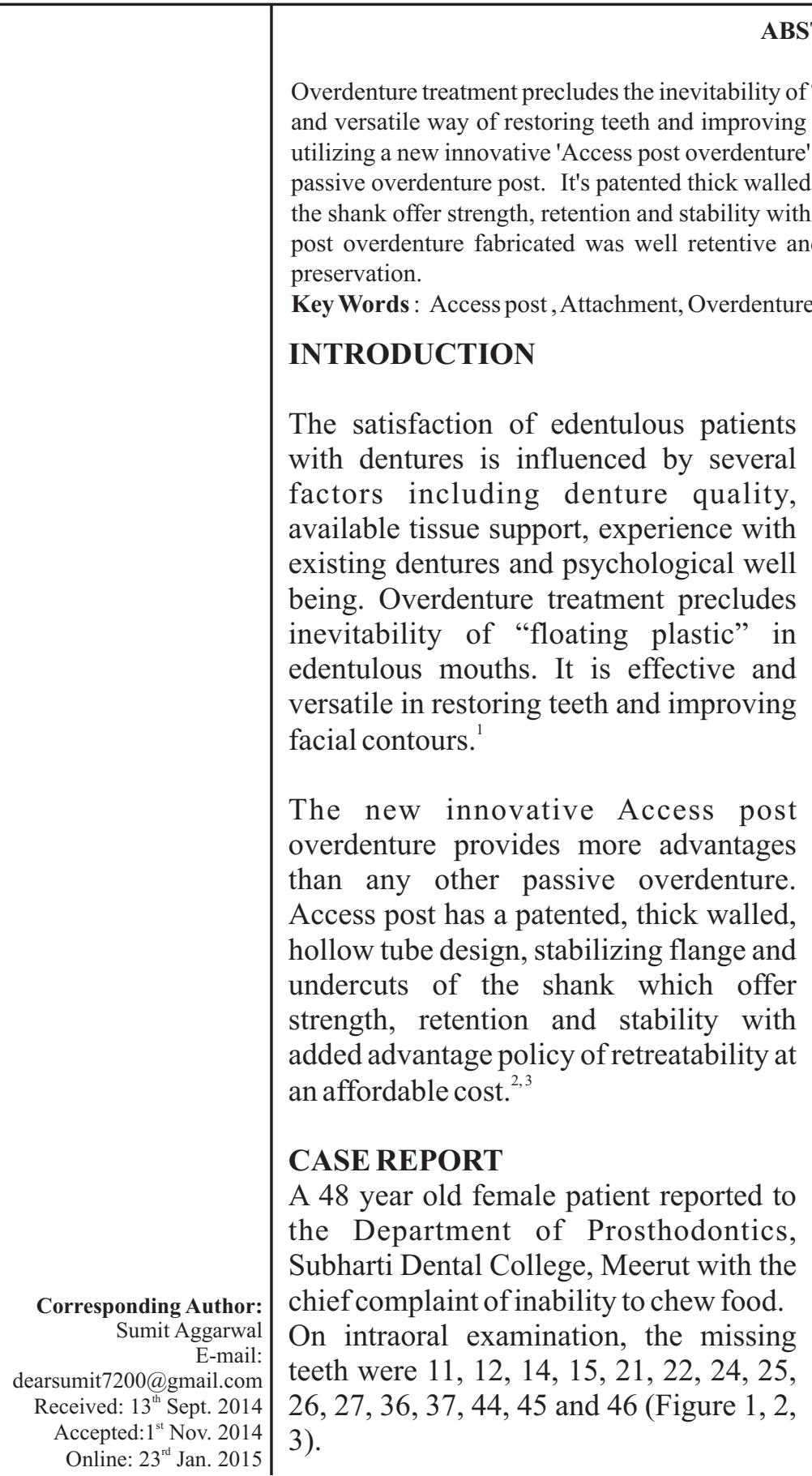

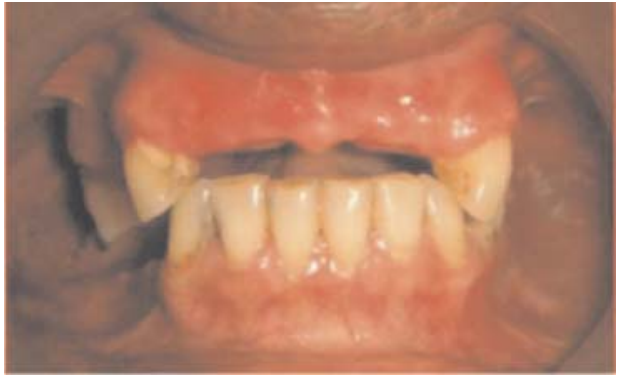

Figure 1: Pre Operative intra-oral view

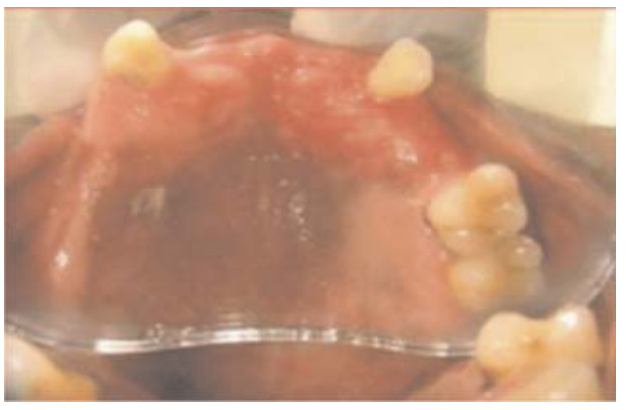

Figure 2: Pre Operative intra-oral view

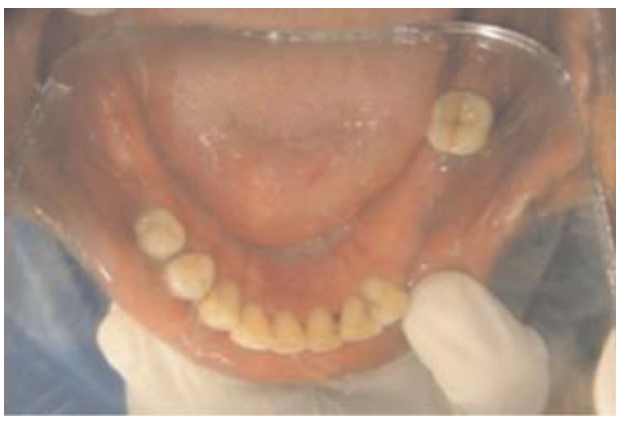

Figure 3: Pre Operative intra-oral view 
Treatment plan for the maxillary arch was Access post overdenture with access posts in teeth no. $13 \& 23$ and cast partial denture for the mandibular arch.

After oral prophylaxis and scaling of existing teeth, intentional Root canal treatment of teeth no. $13 \& 23$ was done. Teeth no. $13 \& 23$ were reduced in height to a level just $1 \mathrm{~mm}$ above the gingiva so as to create the necessary space for Access ball post.

The optimum sizes of posts were selected by holding post over undistorted pre-operative IOPA radiographs of teeth no. 13 and 23 . A $0.5 \mathrm{~mm}$ of lateral root structure at most apical placement of post was considered sufficient for placement. After determining the correct post sizes, post space in both maxillary canines was prepared using a sequence of Gates Glidden drills followed by the color coded primary reamer supplied in the Essential Dental Systems Access post overdenture kit which exactly correlates to post size. After using the primary reamer, the countersink/root facer preparation was done with the countersink/root facer drill provided in the same kit (Figure 4).

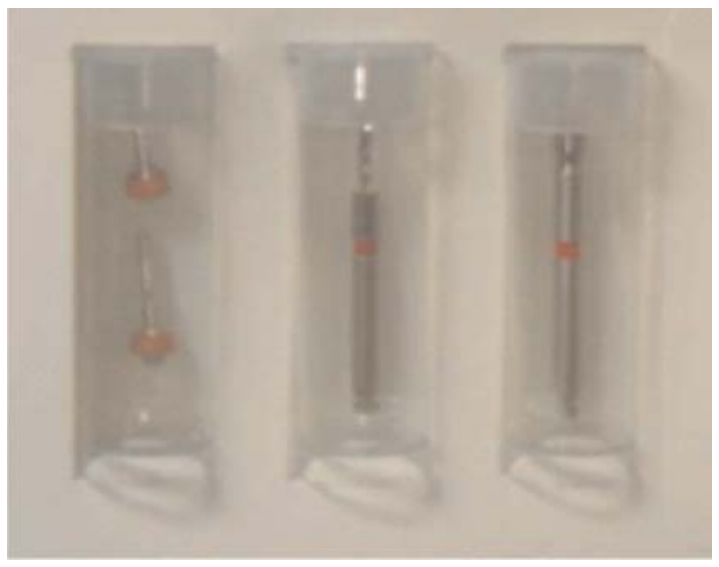

Figure 4: Access post overdenture kit

Subsequently, post space in both canines were irrigated to remove debris and then dried up using paper points. The access posts were initially checked for the fit and then cemented with Type 1 Glass Ionomer Cement (Figure 5,6).

Routine step wise prosthodontic procedure of denture fabrication for upper arch and cast partial denture for
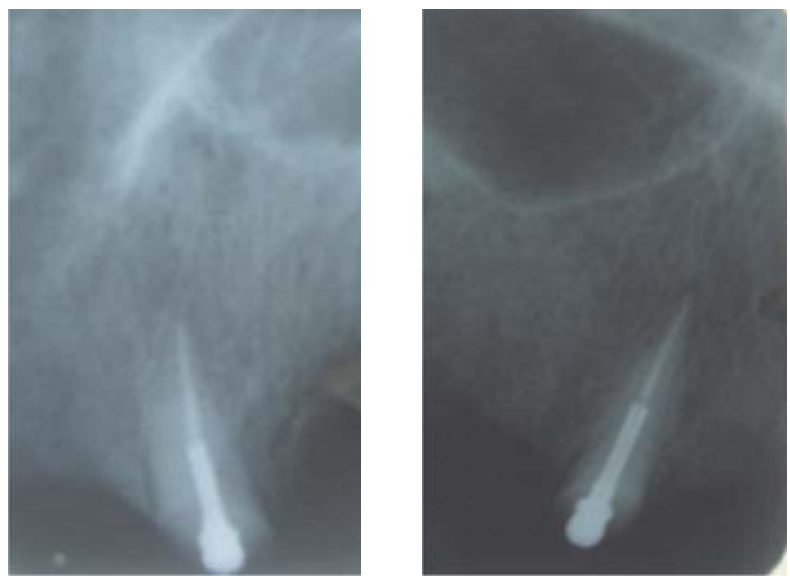

Figure 5 and 6 : IOPA radiographs of 13 and 23 with access posts cemented.

lower arch was carried out. This included making of alginate impressions, border molding of upper arch, mouth preparation for cast partial denture in lower arch teeth, final impressions with addition silicone material followed by recording of jaw relations, try-in and processing of upper denture and lower cast partial denture (Figure 7, 8, 9, 10,11).

Finally, the following chair side procedure was carried out to fit the attachment for the upper denture. The female nylon caps with rubber bands were placed on the male part of the posts (Figure 12). The newly fabricated maxillary denture was marked on its intaglio surface using a disclosing paste and the area was trimmed and sufficiently relieved enough to allow the denture to seat passively over nylon cap (Figure $13,14)$. A doughy mix of cold cure acrylic resin was injected into the relieved area and the denture was seated on the maxillary denture bearing area and was kept in this position until the acrylic hardened. Finally, the denture was finished and polished. The maxillary denture had the added retention supplied by the ball and cap attachment (Figure 15). The post operative results can be appreciated in Figures 16, 17, 18.

\section{DISCUSSION}

The success of the Overdenture treatment depends upon the proper attachment selection for the particular case. Attachment selection is based on available buccolingual and interarch space, amount of bone support opposing dentition, clinical experience, 


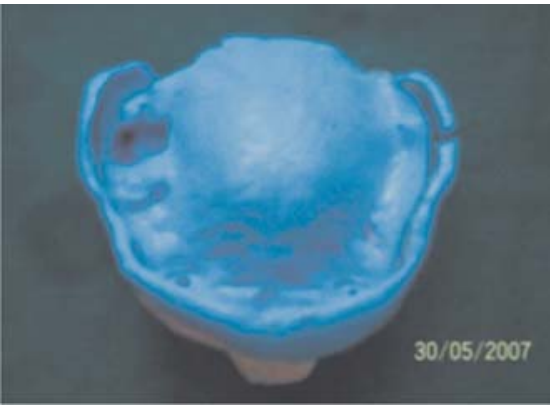

Figure 7: Upper light body addition silicone impression.

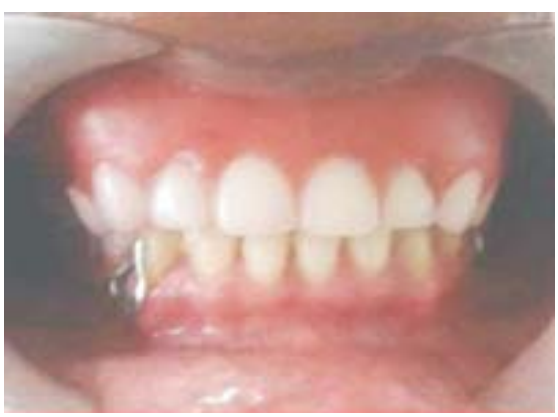

Figure 10: Try in

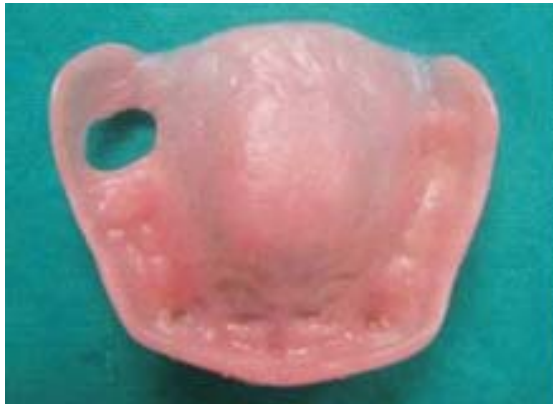

Figure 13: Intaglio surface of maxillary denture.

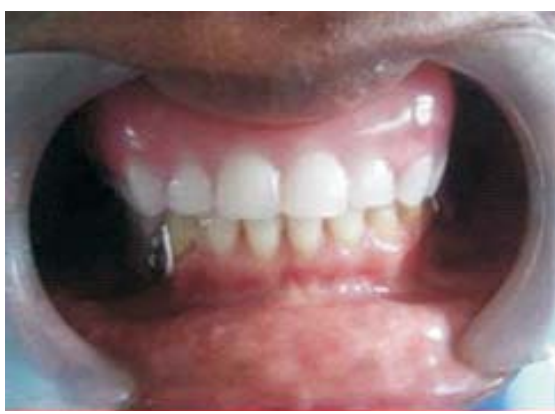

Figure 16: Postoperative intra- oral view

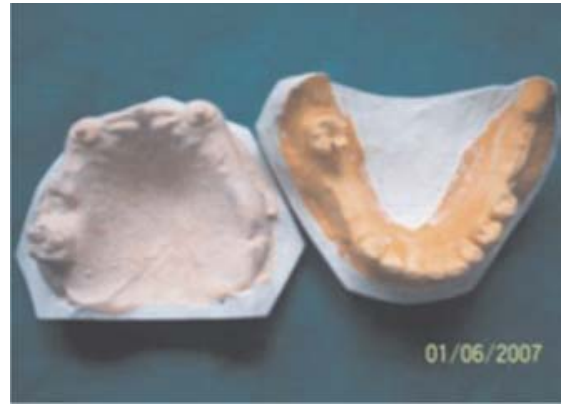

Figure 8: Upper \& lower primary casts.

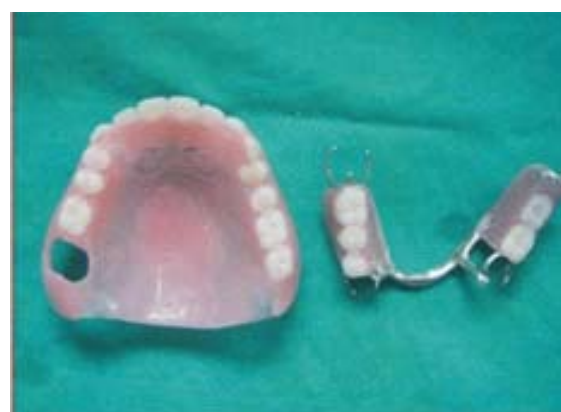

Figure 11: Processed upper and lower dentures.

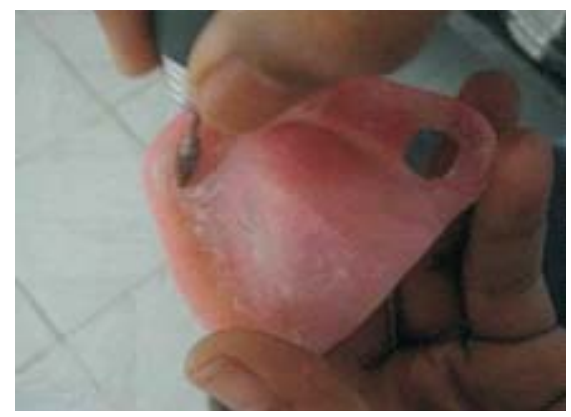

Figure 14: Denture trimming for creating space for attachment.

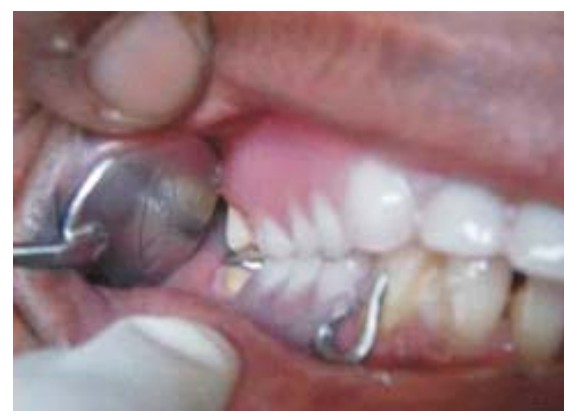

Figure 17: Postoperative intraoral view

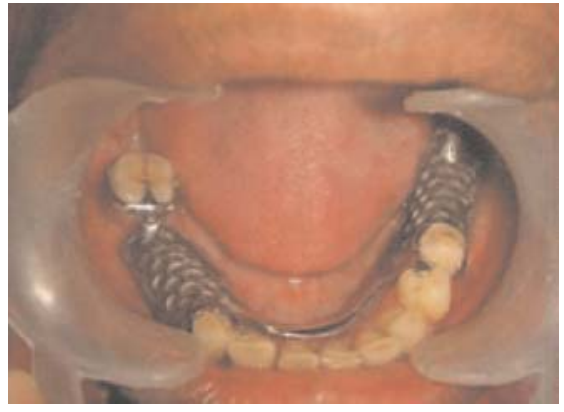

Figure 9: Lower cast partial framework.

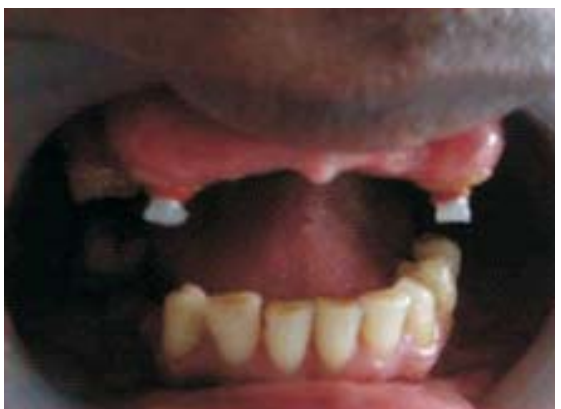

Figure 12: Nylon cap with rubber band placed over ball attachment of Access post.

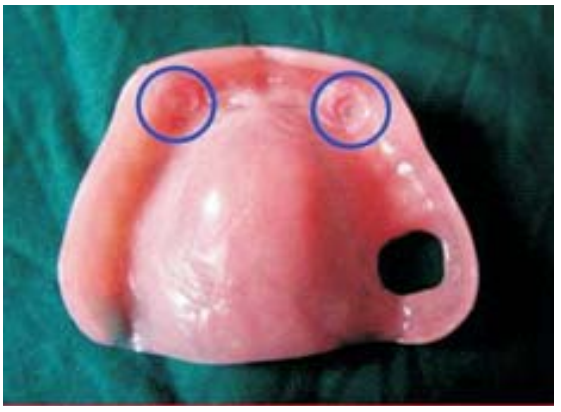

Figure 15: Nylon cap fitted inside maxillary denture with cold cure acylic resin.

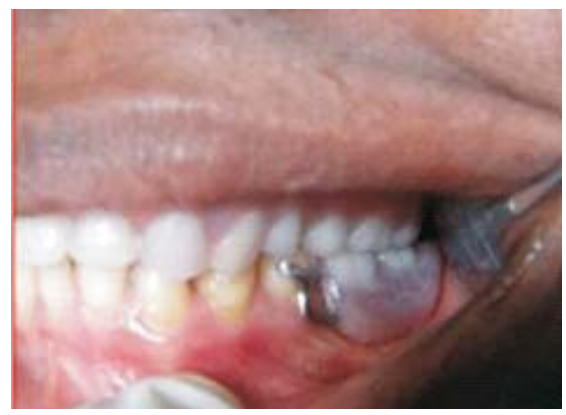

Figure 18: Postoperative intraoral view 
personal preferences, maintenance problems and cost. $^{4,5}$

Access post overdenture is a parallel sided, passive overdenture post that provides easy post removal and access to the apex in the event of a failed root canal. Its thick-walled, hollow tube design provides the strength of a solid shank post. ${ }^{2,6}$ It also vents the hydrostatic pressure of cementation for easier post placement and a more secure cement interface and offers the ability to remove a post, should there be a failed root canal, without surgically widening the canal. ${ }^{7}$ Additionally, the undercuts of the head and shank resist rotation of core material and lock-in post cement to provide high retention of the shank. ${ }^{8,9}$ Access post overdenture is superior to any other passive overdenture since flange and second tier dissipate functional stresses and prevents 'bottoming out' eliminating the high apical functional stresses common to other passive posts. ${ }^{10,11}$

Access post overdenture system is a ball and socket attachment which allows rotation of the denture attachment, hence the posts on different roots do not require parallelism. ${ }^{12}$ The nylon cap provides 3 to 5 pounds of retention. The lab work required is minimal and can be easily done chairside. ${ }^{9,11}$

\section{CONCLUSION}

Access post overdenture is a new overdenture post system which provides more advantages than any other passive overdenture post. The patented thick walled hollow tube design, stabilizing flange and undercuts of the shank offer strength, retention and stability with the added insurance policy of retreatability at a competitive cost.

\section{REFERENCES}

1. Brewer AA, Morrow RM. Overdentures. 2nd ed. St Louis: CV Mosby; 1980.

2. Cohen BI, Deutsch AS, Musikant BL. Cyclic fatigue testing of six endodontic post systems. J Prosthodont 1993;2(1):2832 .

3. Rovatti L, Dallari A, Mason PN. A new system of endodontic retention. Journal of Attualita Dentale 1994;18.

4. Jain DC, Hegde V, Aparna I, Dhanasekar B. Overdenture with access post system: A clinical report. Ind J Dent Res 2011;22(2):359-361.

5. Ivy SS, Robert MM. Overdentures. Principle and procedures. Dent Clin North Am 1996;40(1):169-194.

6. Cohen BI, Condos S, Deutsch AS, Musikant BL. Cyclic fatigue testing of seven endodontic post systems. J Dent Res 1993;72:305.

7. Cohen BI, Pagnillo MK, Condos S, Musikant BL, Deutsch AS. Post removal using a thick-walled hollow tube post design. Oral Health 1994;84(11):15-22.

8. Cohen BI, Musikant BL, Deutsch AS. Comparison of the retentive properties of two hollow post systems to a solid post design. J Prosthet Dent 1993;70(3):234-238.

9. Leung, T, Preiskel HW. Retention profiles of stud-type precision attachments. Int J Prosthodont 1991;4(2):175-179.

10. Cohen BI, Pagnillo MK, Condos S, Deutsch AS. Comparative study of two precision overdenture attachment designs. J Prosthet Dent 1996;76(2):145-152.

11. Sunil D, Neha D. Access post overdenture - a solution for challenging edentulous situation. Bangladesh Journal of Medical Science 2011;10(3): 203-205.

12. Epstein DD, Epstein PL, Cohen BI, Pagnillo MK. Comparison of the retentive properties of six prefabricated post overdenture attachment systems. J Prosthet Dent 1999;82(5):579-584. 